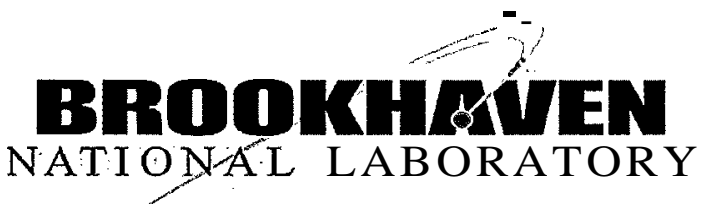

BNL-73402-2005-CP

\section{Summary on Titanium Nitride Coating of SNS Ring Vacuum Chambers}

\author{
R. Todd, P. He, H.C. Hseuh, D. Weiss \\ To be presented at Particle Accelerator Conference \\ Knoxville, Tennessee \\ May, 16-20, 2005
}

\section{Collider-Accelerator Department}

BROOKHAVEN NATIONAL LABORATORY

P.O. BOX 5000

Upton, NY 11973-5000 *

www.bnl.gov

Managed by.

Brookhaven Science Associates, LLC

for the United States Department of Energy under

Contract No: DE:AC02-98CH10886: 


\section{DISCLAIMER}

This report:was prepared as an account of work sponsored by an agency of the United States Government. Neither the United States Government nor any agency thereof, nor; any of their employees, nor any of their contractors, subcontractors, or their employees, makes any warranty, express or implied, or assumes any legal .liability or responsibility for the accuracy, completeness, or any third party's use or the results of such 'use of any information, apparatus, product, or process disclosed, or represents that its use would not infringe privately owned rights. Reference herein to any specific commercial product, process, or service by.trade name, trademark, manufacturer, or otherwise, does not ' necessarily: constitute or imply its endorsement, recommendation; or favoring by the United States Government or any agency thereof or its contractors or subcontractors. The views and opinions of authors expressed herein do not necessarily state or reflect those of the United States Government or any agency thereof.: , 


\title{
SUMMARY ON TITANIUM NITRIDE COATING OF SNS RING VACUUM CHAMBERS*
}

\author{
R. Todd ${ }^{\dagger}$, P. He, H.C. Hseuh and D! Weiss; BNL, Upton, NY 11973,U.S.A.
}

\section{Abstract}

The inner: surfaces of the $248 \mathrm{~m}$ Spallation Neutron Source (SNS) accumulator ring vacuum chambers are coated with $\sim 100 \mathrm{~nm}$ of titanium nitride (TiN) to reduce the secondary electron yield (SEY) of the chamber walls. There are approximately 135 chambers and kicker modules, some up to $5 \mathrm{~m}$ in length and $36 \mathrm{~cm}$ in diameter, coated with TiN. The coating is deposited by'means of reactive DC magnetron sputtering using a cylindrical cathode with internal permanent magnets. This cathode configuration generates a deposition- rate sufficient to meet the required production schedule and 'produces stoichiometric films with good adhesion, low SEY and acceptable outgassing. Moreover, the cathode magnet configuration allows for simple changes in length and has been adapted to coat the wide variety of chambers and components contained within the' arcs, injection, extraction, collimation and RF straight sections. Chamber types and quantities as well as the cathode configurations are presented herein. The unique coating requirements of the injection kicker ceramic chambers and the extraction kicker ferrite surface will be emphasized. A brief summary of the salient. coating properties is given including the interdependence of SEY as a function of surface roughness and its effect on outgassing.

\section{INTRODUCTION}

On April 26, 2005; Brookhaven coated the final SNS accumulator ring vacuum chamber with :TiN: A total of 135 discrete vacuum components (including spares) and over $300 \mathrm{~m}$ in length were coated. These chambers range. from 20 to $36 \mathrm{~cm}$ in diameter and from $<0.5 \mathrm{~m}$ to $5 \mathrm{~m}$ in . lengths .

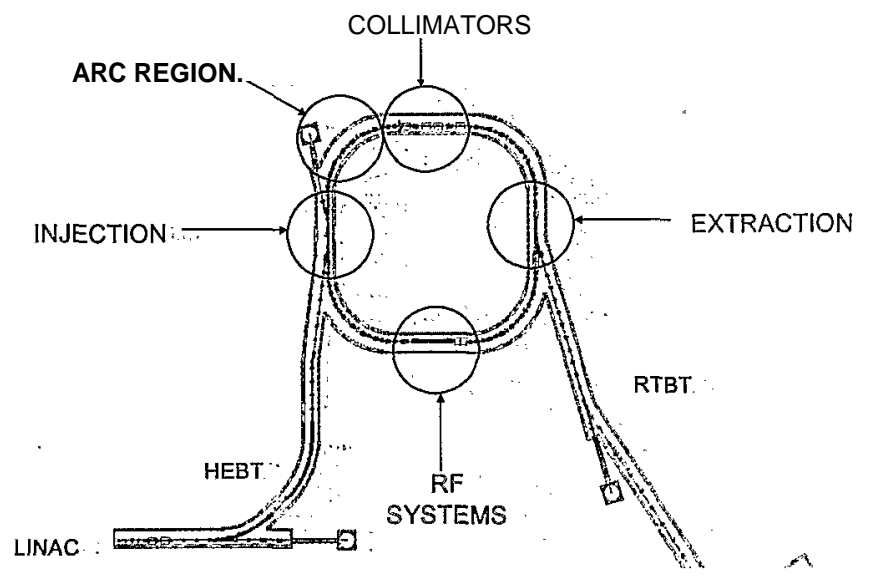

Figure 1. SNS accumulator ring layout.

The accumulator ring, shown in Figure 1, consists of four arc regions and four straight. sections; injection, collimation; i extraction and RF. A summary of the types and quantities of coated chambers from each region is given in Table 1.

\begin{tabular}{c|r}
\multicolumn{1}{c|}{ ARC } & \multicolumn{1}{|c}{ INJECTION } \\
\hline \hline Half-Cell A (9) & ceramic pipe (10) \\
Half-Cell B (9) & pump tee (2) \\
Half-Cell C (9) & bellows (6) \\
Half-Cell D (9) & quad doublet (3) \\
Half-Cell E (5) & chicane chambers (4)
\end{tabular}

\begin{tabular}{r|r|r} 
COLLIMATION & EXTRACTION & \multicolumn{1}{c}{ RF } \\
\hline \hline primary coll (1) & K1 modules (7) & cavity chamber (15) \\
coll 2 \& 3 (2) & K2 modules (7) & quad doublet (3) \\
quad doublet (3) & quad doublet (4) & IPM (2) \\
bellows (3) & lambertson (1) & bellows (3) \\
drift chamber (2) & bellows (1) & beam cur mon (1) \\
pump tee (1) & beam in gap kick (1) & wall cur mon (1) \\
tune pickup (1) & drift chamber (1) & tune kicker (1) \\
QMM pickup (1) & pump tee/spool (3) & QMM pickup (1) \\
damper kick (2) & & spool piece (1)
\end{tabular}

\section{COATING METHOD}

Reactive DC magnetron sputtering, with its high deposition rate, was chosen over diode sputtering to facilitate the coating of these vacuum chambers [1]. The cathode configuration used is similar to the one reported by Hosokawa et al [2]. A schematic of this cathode configuration and BNL's cathode is shown in Figure 2. A deposition rate of $-100 \mathrm{~nm} / \mathrm{hr}$ at a cathode power density of 0.625 watts $/ \mathrm{cm}^{2}$ was achieved during development with a $20 \mathrm{~cm}$ diameter chamber. For production coating; discharge power was varied linearly with the chamber length (i.e.: magnet string length), and the deposition time varied with the diameter. Increasing the power density above $1 \mathrm{watt} / \mathrm{cm}^{2}$ level would cause heat damage to the nitrogen distribution tube, which was not well thermal anchored with the water cooled cathode. Without that concern much higher deposition rates could be achieved: :

\footnotetext{
*SNS is managed by UT-Battelle, LLC, under contract DE-AC0500OR22725 for the U.S. Department of Energy. SNS is a partnership of six national laboratories: Argonne, Brookhaven, Jefferson, Lawrence Berkeley, Los Alamos, and Oak Ridge. This work is performed under the auspices of the U.S. Department of Energy. ${ }^{t_{\text {rtodd@binl.gov }}}$
} 


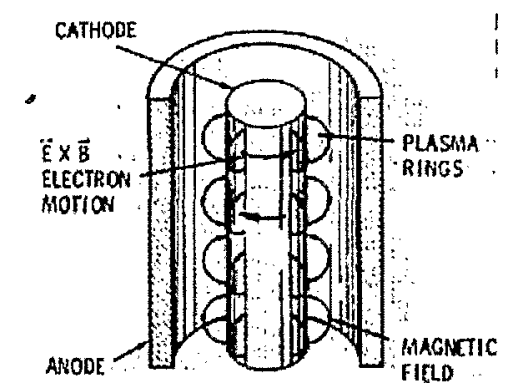

a

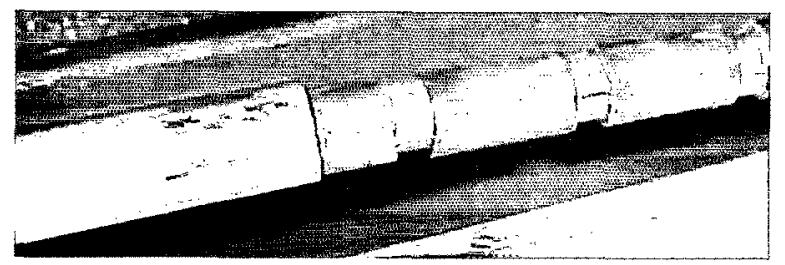

b

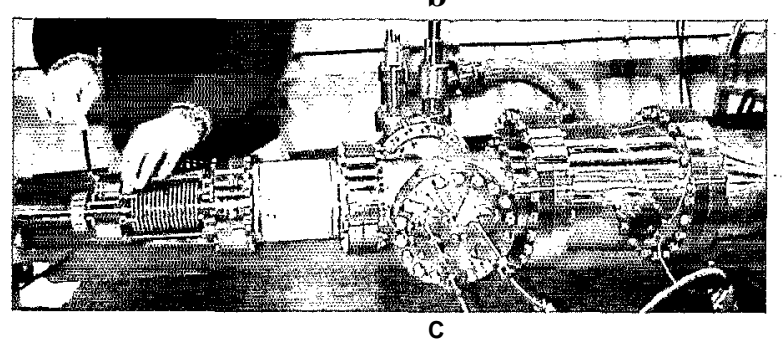

Figure 2. (a) Schematic of the cathode configuration. reported by Thornton [3]. (b) Ti tubing and Alnico magnets used to .construct. BNL cathode. (c) Cathode leveling and isolation. •

\section{CATHODE CONFIGURATIONS}

This magnetron cathode could be easily adapted to a wide range of chamber sizes and geometries. Adjustments in length could be made by simply adding or removing), magnets.. There were four major configurations required to coat all the SNS ring " chambers: Arc half-cell chambers; Straight section metal chambers; Injection ceramic chambers; and Extraction kicker modules. In all configurations, the cathode was isolated from the chamber using ceramic breaks. Bellows were also used for $m$. alignment and centering of the cathode (Figure 2(c)). Cathode deflection can be reduced by applying a bending . moment to the cathode. ,

\section{Arc Half-Cell Chambers}

Due to the Half-cell chamber geometry, a cathode was constructed with a sagitta equal to the dipole arc section: Due to the difference in nitrogen consumption rate resulting from the difference in cathode-to-chamber spacing between the dipole half and quadrupole half, independent flow control was required. A schematic of the coating setup for arc half-cell chambers is shown in Figure 3.

\section{Straight Section Metal Chambers}

The coating of straight chambers iwas much like the half-cell chambers. In the case of short chambers sharing like flanges, they could be joined together and coated in batches. Three cathodes were constructed which would $\mathrm{s}$. coat chambers $2 \mathrm{~m}, 3.5 \mathrm{~m}$ and $5 \mathrm{~m}$ in length.. In certain cases, spool pieces would-be installed to make up the differences in length..

The cathode used to coat the $5 \mathrm{~m}$ injection and $\mathrm{RF}$. doublet chambers, was made from thick wall 1.25" diameter schedule $\mathbf{4 0}$ Ti pipe. This stiffer cathode reduced the deflection by a factor of 2. Special collars were fabricated to transfer the increased bending moment stress applied to the ceramic break end cuffs when leveling the cathode. Two independent nitrogen tubes were also used to help better control the process.

\section{Injection Kicker Ceramic Chambers}

The coating of the injection kicker ceramic chambers posed a unique set of problems [4]: Because the ceramic chambers could not couple the discharge to the cathode, a stainless steel anode screen was placed between the cathode and ceramic chamber. The screen allowed uniform discharge along the cathode but created a nonuniform coating due to shadowing. This shadowing was a form of destructive interference between the discharge ring spacing on the cathode and the screen. Several tests were conducted with various screen sizes and countered intuitively, a smaller screen size yielded the best result. The OFHC.Cu cathode, anode screen and magnet string are shown in Figure 4. The coating system isolated the ceramic chamber with additional ceramic breaks so in-situ resistance measurements could be taken during the coating.

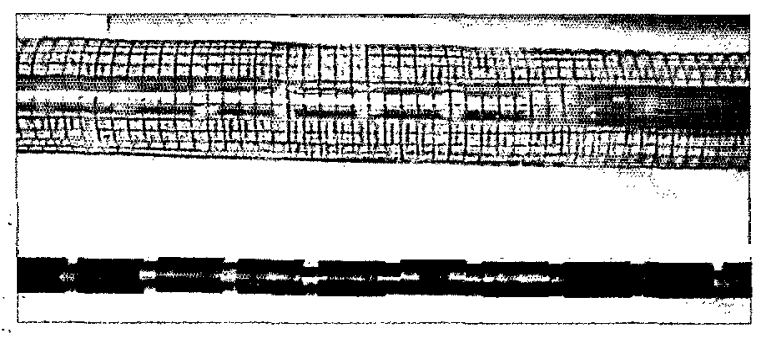

a

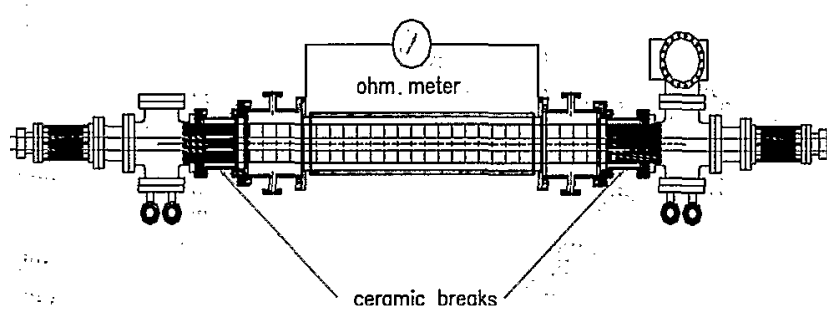

b

Figure 4. (a) Copper cathode, anode screen and magnet string. (b) Schematic of set up showing electrical isolation of ceramic pipe for in-situ resistance measurements.. 


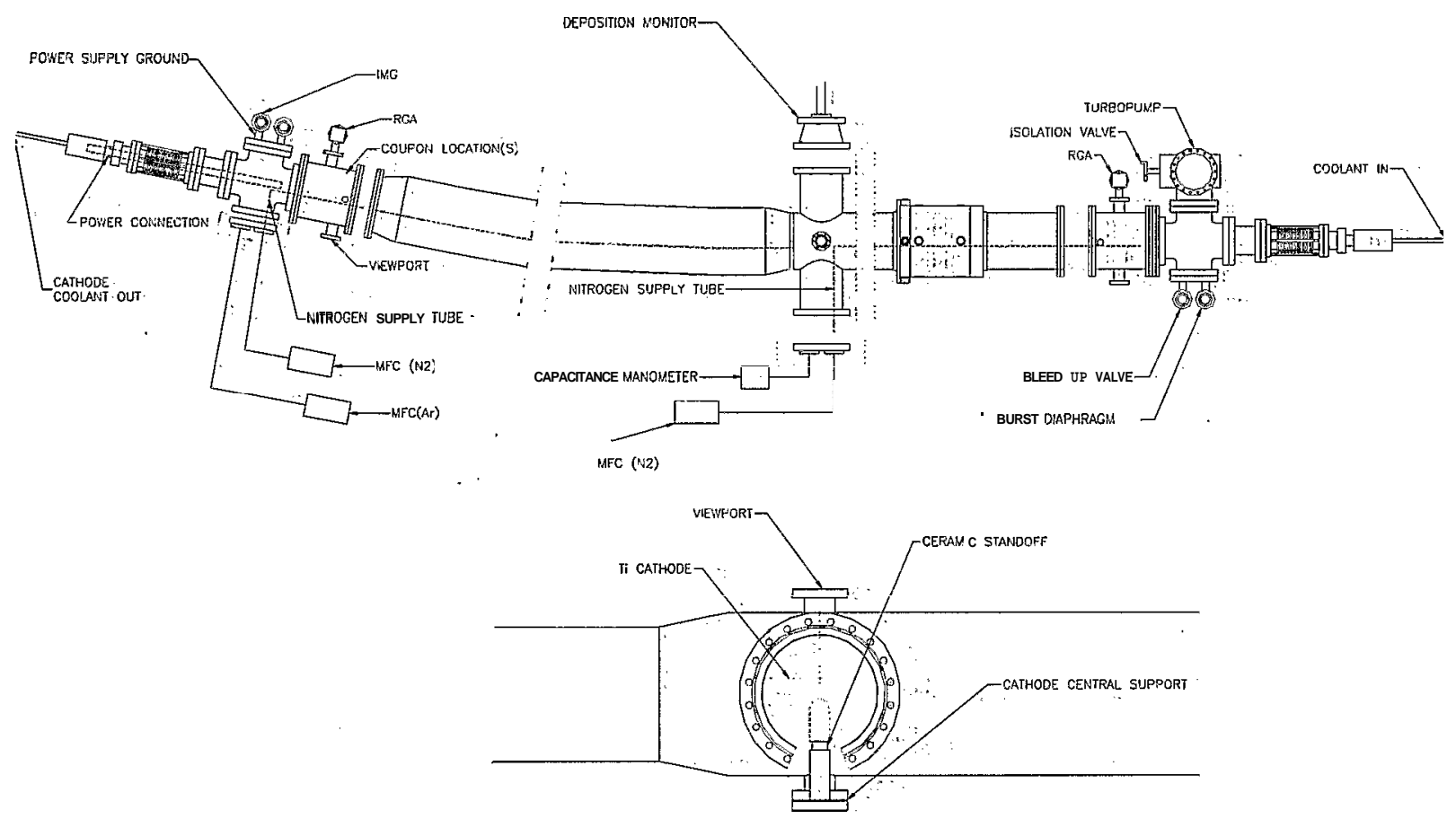

Figure 3. Schematic of magnetron sputtering setup for arc half-cell chambers. The lower portion showing the central cathode support. (IMG: inverted magnetron gauge, RGA Residual gas analyzer, MFC: Mass flow controller)

\section{Extraction Kicker:Modules}

The coating, on the ferrite surface of the extraction kicker modules needs to have low SEY:and minimum induced eddy current heating [4]: :An estimate of the coating uniformity, was made based on a cosine approximation (Figure 5). The results raised concern that the uniformity of the TiN coating on the vertical ferrite walls would be unacceptable..However,.testing showed only a $4 \mathrm{x}$ difference in thickness from the midplane to the corner..

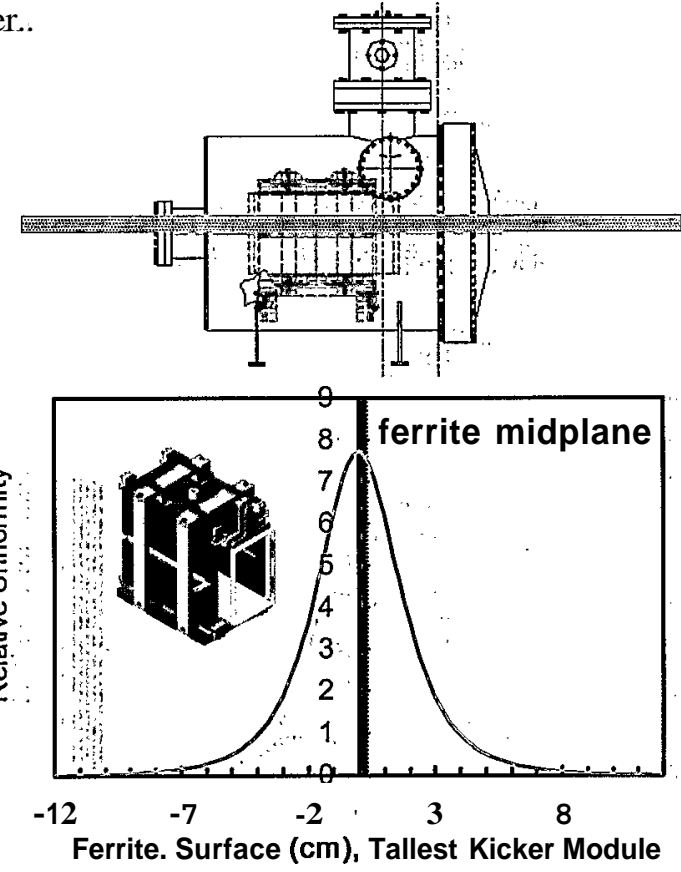

Figure 5. Coating, schematic for extraction kicker modules and uniformity approximation.

\section{SEY AND OUTGASSING}

The measured SEY of coated chambers was found to be dependent on surface roughness [5]. A rougher surface yields lower SEY values, however these coatings were found to have a higher outgassing rate than coatings produced at lower pressure [6]: For SNS chambers, low SEY was of primary importance. Consequently; rougher coating surfaces were produced at a higher, sputtering. pressures (i.e. -5 mTorr), which yielded SEY values in the 1.6 to 1.8 range.

\section{ACKNOWLEDGEMENTS}

The authors would like to thank the ColliderAccelerator Vacuum Group for their tireless effort; in meeting the SNS coating production schedule.'

\section{REFERENCES}

[1] R. Todd, et al; Proc. PAC01. p2159 (2001).

[2] N. Hosokawa, T. Tsukada, T. Misumi, J. Vac. Sci. Technol., 14, 143 (1977).

[3] J. Thornton, J. Vac. Sci. Technol., 15, 171 (1978). .

[4] H.C. Hseuh et al, Physical and Electromagnetic Properties of customized coatings for SNS Injection Ceramic Chambers and Extraction Ferrite Kickers, these proceedings..

[5] P. He, et al, Proc. PAC2003; p788 (2003).

[6] P. He, et al, J. Vac. Sci. Technol. A22, 705 (2004). 